\title{
Características de um bom professor na concepção dos acadêmicos do Curso de Odontologia da Universidade do Vale do Itajaí - UNIVALI
}

\author{
Luciane Campos*, Rossiny Valério Orsi**, Elisabete Rabaldo Bottan***, Mário \\ Uriarte Neto****
}

\author{
* Mestre em Saúde e Gestão do Trabalho, professora e pesquisadora \\ do Grupo Atenção à Saúde Individual e Coletiva em Odontologia \\ do Curso de Odontologia da Universidade do Vale do Itajaí \\ ** Acadêmico do Curso de Odontologia da Universidade do Vale do \\ Itajaí, Bolsista de Programa de Iniciação Científica \\ *** Mestre em Educação e Ciências, professora e pesquisadora do \\ Grupo Atenção à Saúde Individual e Coletiva em Odontologia do \\ Curso de Odontologia da Universidade do Vale do Itajaí \\ **** Doutor em Engenharia de Produção - Ergonomia, professor e \\ pesquisador do Grupo Atenção à Saúde Individual e Coletiva em \\ Odontologia do Curso de Odontologia da Universidade do Vale do \\ Itajaí
}

\section{RESUMO}

Este estudo teve por objetivo conhecer as características do professor ideal na concepção dos acadêmicos do Curso de Odontologia da Universidade do Vale do Itajaí (UNIVALI). Foi um estudo exploratório delineado segundo norteadores da pesquisa qualitativa. A coleta de dados foi estruturada com base nos princípios do Teste de Associação Livre de Palavras, tendo como estímulo indutor a expressão professor ideal para mim é. O participante deveria relacionar até oito (8) palavras que, em sua concepção, definiriam o bom professor. A coleta foi conduzida por um único pesquisador. Para a análise dos dados foram definidas cinco categorias. Participaram da pesquisa 225 acadêmicos matriculados do primeiro ao último período do curso, no segundo semestre de 2010. Para os acadêmicos, os principais atributos de um professor ideal são: habilidades sociais e interpessoais $(37,9 \%)$, habilidades pedagógicas (25,9\%), habilidades cognitivas $(14,7 \%)$, habilidades organizacionais $(14,1 \%)$ e ser ético $(7,5 \%)$. Com base nos resultados obtidos, concluiu-se que, para os acadêmicos, o bom professor não é somente aquele que tem características relacionadas ao conhecimento disciplinar e pedagógico, mas sim, aquele que apresenta habilidades sociais e interpessoais, sendo organizado, manifestando postura ética e compromisso profissional.

\section{DESCRITORES}

Docentes. Educação em odontologia. Educação superior.

$\Delta$ educação tem por finalidade o pleno desenvolvimento do educando, seu preparo para o exercício da cidadania e sua qualificação para o trabalho. Os aspectos jurídicos dos processos de reformulação do ensino superior, no Brasil, foram ratificados na Lei de Diretrizes e Bases da Educação (LDB) que define a educação como processos de formação durante o desenvolvimento da vida de cada ser humano na família, no trabalho, nas instituições de ensino e pesquisa, movimentos sociais, organizações da sociedade civil e manifestações culturais. Com relação à educação superior, a LDB destaca a necessidade de estimular o conhecimento do acadêmico acerca dos problemas do mundo presente, prestar serviços à comunidade e estabelecer com esta uma relação de reciprocidade. Neste contexto, a educação deve se vincular ao mundo do trabalho e à pratica social. ${ }^{4}$ 
A formação de profissionais para a área da saúde enfrenta um importante desafio, que consiste no desenvolvimento de estratégias para consolidar um ensino voltado à humanização e à integralidade da atenção contemplando o paradigma da promoção da saúde. Este processo deve ser baseado nas novas concepções de saúde-doença e centrado em uma perspectiva universalista que deve incluir o desenvolvimento técnico-científico, mas que, também, permita que o conhecimento adquirido ao longo da formação universitária atenda às reais necessidades da população. ${ }^{22}$

Para melhorar a qualidade da educação no ensino superior é preciso investigar os cursos universitários de formação profissional. Como em qualquer curso superior, a qualidade do ensino de odontologia está relacionada a um adequado modelo pedagógico tanto da universidade como do curso. Além disso, a qualificação e a atualização permanente (tanto técnica quanto didático-pedagógica) do corpo docente são essenciais para proporcionar a formação de um profissional generalista, humanista, crítico e reflexivo, comprometido com as questões sociais, e a promoção da saúde, necessidades estas apontadas pelas Diretrizes Curriculares Nacionais (DCNs). ${ }^{11}$

Identificar, avaliar e desenvolver as competências necessárias para melhorar a qualidade da formação dos profissionais de saúde de acordo com as DCNs é, sem dúvida, um grande desafio. Para superar este desafio são necessárias mudanças na gestão e concepção dos processos educativos. A tendência de mudar a concepção dos processos educacionais abandonando o modelo centrado no professor em busca de um paradigma centrado na figura do aluno implica, necessariamente, em uma mudança no papel dos professores no desenvolvimento das competências promulgadas pelas DCNs na formação acadêmica.

Emergem destas reflexões questões relacionadas ao modo como essas mudanças serão percebidas pelos acadêmicos e quais são os atributos ou qualidades do bom professor na perspectiva deles. A partir destes questionamentos e devido à grande importância e influência do perfil do professor na formação profissional do futuro cirurgião-dentista, optou-se por este estudo com o objetivo de conhecer as características do professor ideal na concepção de acadêmicos do Curso de Odontologia da UNIVALI.

\section{MATERIAIS E MÉTODOS}

Esta investigação se caracterizou como estudo exploratório delineado segundo norteadores da pesquisa qualitativa.
A população-alvo foi composta pelos 330 acadêmicos regularmente matriculados do primeiro ao último período do Curso de Odontologia da Universidade do Vale do Itajaí - UNIVALI, no segundo semestre de 2010. A amostra foi não probabilística, tendo sido obtida por conveniência, dentre os alunos que, por livre e espontânea vontade, aceitaram participar da pesquisa.

A coleta de dados foi estruturada com base nos princípios do Teste de Associação Livre de Palavras" tendo como estímulo indutor a expressão professor ideal para mim é. O participante, a partir do estímulo indutor deveria relacionar até oito palavras que, em sua concepção, definiriam um bom professor. A coleta foi conduzida por um único pesquisador, no segundo semestre de 2010.

Os acadêmicos foram abordados em sala de aula, de forma coletiva, quando lhes foram explicitados os objetivos e procedimentos da pesquisa. Aqueles que concordaram participar receberam uma folha contendo a questão indutora. No momento da aplicação do instrumento de coleta de dados o pesquisador tomou o cuidado no sentido de não exercer nenhum tipo de interferência nas respostas dos participantes da pesquisa.

Por tratar-se de uma pesquisa envolvendo seres humanos, foram respeitados os preceitos éticos da resolução 196/96, através do aceite e assinatura de um termo de consentimento livre e esclarecido. A pesquisa foi submetida ao Comitê de Ética em Pesquisa (CEP) da UNIVALI, tendo sido aprovada pelo parecer $76 / 10$.

Para a análise dos dados, foram definidas categorias nominais, de acordo com as características apontadas pelos participantes. As cinco categorias e os respectivos termos identificadores estão dispostos no Quadro 1. Para cada categoria, foi calculada a frequência relativa.

\section{RESULTADOS}

Participaram da pesquisa 225 acadêmicos, ou seja, 68,2\% da população-alvo. Após a coleta e análise preliminar dos dados foi possível identificar, entre as respostas emitidas pelos participantes, cinco categorias. O Quadro 1 apresenta estas categorias e as expressões que as qualificavam.

A frequência de cada uma das categorias que expressam as características de um bom professor, na concepção dos acadêmicos, pode ser observada no Quadro 2. 
Quadro 1 - Características que mais apareceram nas citações dos acadêmicos associadas às respectivas categorias.

\begin{tabular}{|l|l|}
\hline \multicolumn{1}{|c|}{ Categorias } & \multicolumn{1}{c|}{ Qualidades Citadas } \\
\hline $\begin{array}{l}\text { Habilidades Sociais } \\
\text { e Interpessoais }\end{array}$ & $\begin{array}{l}\text { Amigo da turma, compreensivo, } \\
\text { simpático, educado, paciente, } \\
\text { acessível, atencioso }\end{array}$ \\
\hline $\begin{array}{l}\text { Habilidades } \\
\text { Pedagógicas }\end{array}$ & $\begin{array}{l}\text { Comunicativo, ter boa oratória, } \\
\text { dinâmico, rigoroso, saber passar } \\
\text { matéria }\end{array}$ \\
\hline $\begin{array}{l}\text { Habilidades } \\
\text { Cognitivas }\end{array}$ & $\begin{array}{l}\text { Inteligente, ter o conhecimento, ser } \\
\text { informado }\end{array}$ \\
\hline $\begin{array}{l}\text { Habilidades } \\
\text { Organizacionais }\end{array}$ & $\begin{array}{l}\text { Organizado, responsável, pontual, } \\
\text { objetivo } \\
\text { Ética }\end{array}$ \\
\hline
\end{tabular}

Quadro 2 - Distribuição das frequências das categorias identificadoras do professor ideal na concepção dos acadêmicos participantes da pesquisa.

\begin{tabular}{|l|c|c|}
\hline \multicolumn{1}{|c|}{ Categorias } & N & $\%$ \\
\hline Habilidades Sociais e Interpessoais & 667 & 37,9 \\
\hline Habilidades Pedagógicas & 456 & 25,9 \\
\hline Habilidades Cognitivas & 259 & 14,7 \\
\hline Habilidades Organizacionais & 248 & 14,1 \\
\hline Ética & 132 & 7,4 \\
\hline
\end{tabular}

\section{DISCUSSÃo}

A educação superior deve conduzir ao permanente desenvolvimento de aptidões para a vida produtiva nas diferentes áreas, incentivando o trabalho, a pesquisa e a investigação científica, promovendo a divulgação de conhecimentos culturais, científicos e técnicos. E, a formação do quadro docente para magistério superior faz-se através de pós-graduação, sendo necessária a defesa de uma dissertação, para o nível de mestrado, e da tese para o nível de doutorado.

No entanto, a titulação de mestre e/ou doutor não garante conteúdos e vivências compatíveis com a formação de recursos humanos para a atividade docente. Cada professor traz consigo uma bagagem própria com diferentes valores, interesses, necessidades e dificuldades. A capacitação para a docência resulta de um processo complexo e contínuo de preparo técnico, teórico e pedagógico, devendo ser estudada e compreendida dentro de múltiplos cenários: técnico, econômico, político, social, ético, histórico e psicológico. $5,8,16,18,19$

Para os alunos, o docente tem papel fundamental no processo ensino-aprendizagem, sendo considerado o responsável pela transmissão de conhecimento e experiência, além de ensinar, tirar dúvidas e orientar tanto no âmbito teórico como na prática. Depen- dendo de suas atitudes o professor pode fazer com que o aluno se interesse, ou não, por determinada disciplina. Logo, a relação aluno-professor pode tanto exercer um efeito motivador quanto desmotivador, alterando o nível de esforço e empenho do aluno. ${ }^{9-11,16}$

Neste estudo com os acadêmicos do curso de Odontologia da UNIVALI, aspectos relativos às habilidades cognitivas, inerentes ao objeto de cada disciplina, associados às habilidades pedagógicas e às organizacionais alcançaram uma frequência expressiva $(54,7 \%)$. $\mathrm{E}$, as habilidades sociais e interpessoais juntamente com os aspectos referentes à ética atingiram 45,3\% .

A aproximação das frequências destas categorias revela a importância que os acadêmicos atribuem a um professor que seja competente do ponto de vista técnico, mas, também, social e eticamente comprometido. Sem dúvida, o professor é importante agente do processo de formação profissional e suas características têm significativo impacto na qualidade do ensino. Acredita-se que nada tem maior efeito na aprendizagem do que a presença de um excelente professor, não só pela transmissão do conhecimento, mas também como contribuinte na formação do estudante-cidadão. O ensino, na atualidade, requer um professor-educador que perceba o aluno como parceiro; havendo, portanto, a necessidade de participação e diálogo entre estes sujeitos. Assim, o professor deve atuar como facilitador e mediador do processo ensino-aprendizagem e não como única fonte de conhecimento., 2,10,11,14,16,17

O modo de ser do professor, seu jeito de pensar, agir e sentir irá repercutir no comportamento dos alunos, bem como a imagem que o aluno tem do professor irá interferir em sua ação. A característica mais importante do bom professor para o aluno está ligada ao aspecto relacional. Assim, a confiança do aluno em ter no professor um amigo que possa, junto com ele, construir conhecimento é mais significativa que a competência do professor em ministrar aulas. Habilidades sociais e interpessoais, com ênfase no bom relacionamento e na postura atenciosa do professor, são qualidades desejáveis no docente. . $7,10,11,16,17,19,20^{2}$

Atributos como ser justo, paciente, calmo, compreensivo, simpático, amigável, gente boa, foram características citadas pelos acadêmicos desta e de outras pesquisas, o que reflete a importância que os estudantes conferem ao desenvolvimento de habilidades interpessoais e ao desenvolvimento de atitudes pessoais que se relacionam com o aprender a ser e o saber conviver na aprendizagem. .,10,11,16,21 $^{-1}$

Quando o professor estabelece vínculo, o relacionamento se torna mais confiável, pois permite que 
haja uma maior interrelação. É importante que a aprendizagem tenha conteúdo significativo vivencial, utilizando o afetivo e o intelectual de forma harmônica e que ao longo da vida acadêmica o aluno consiga sua autorrealização de forma permanente. Assim, o ensino pautado em competências e habilidades deve superar o saber fazer e o aprender a conhecer e deve abranger o aprender a ser e aprender a conviver., ${ }^{7,20}$

Outra característica que os sujeitos deste estudo, também, evidenciaram foi a habilidade pedagógica. A habilidade pedagógica se expressa no preparo do professor e em sua capacidade de explicar o conteúdo. Bom professor é aquele que consegue passar o conteúdo com empolgação, aquele que consegue manter a sala toda incentivada através de explicações magníficas sem fugir do assunto principal. Este deve possuir uma linguagem acessível e adequada mantendo os discentes sempre atentos, utilizando estratégias lúdicas e de motivação à participação. ${ }^{3,6,7,17-21}$

Apesar da importância do componente pedagógico na formação de um bom professor, se observa que, frequentemente, os docentes na área da saúde não têm formação pedagógica. A construção do professor, geralmente, se faz com base no modelo de professores com os quais conviveu ao longo de sua vida estudantil, modificando alguns destes padrões por seus interesses, experiência e/ou bom senso. ${ }^{13}$ Neste cenário, alguns professores se mostram resistentes a mudanças e continuam a ensinar ignorando as novas metodologias de ensino-aprendizagem. Desenvolver abordagens pedagógicas construtivas de ensino-aprendizagem requer a formação de docentes mais críticos e comprometidos com o seu próprio processo de construção de conhecimento. ${ }^{1}$

No processo educativo devem ser consideradas as duas principais categorias de sujeitos nele envolvido, que são o professor e o aluno. Assim, distintas posturas dos docentes e dos discentes podem ocorrer. Para os alunos mais tradicionais, o processo ensino-aprendizagem é facilitado quando o professor mostra-se mais diretivo e o bom professor é aquele que explica a matéria com clareza, apresenta o assunto de forma ordenada, tem bom domínio do assunto, estando sempre atualizado e disposto a esclarecer dúvidas. Já, para os alunos mais participativos, o professor facilita o processo ensino-aprendizagem através do despertar da curiosidade, questionando e estimulando a capacidade critica e reflexiva, do aluno. ${ }^{7,19-21}$

É importante que o professor reflita sobre suas atitudes pedagógicas, buscando cada vez mais se qualificar, estimulando o interesse coletivo dos alunos.
Ao refletir sobre sua atuação educativa, o professor deve ter conhecimento de alguns dos atributos que são considerados como importantes; são eles:

- envolvimento,

- dedicação no trabalho,

- respeito,

- responsabilidade e pontualidade.

O profissional da educação deve ter uma mente aberta, deve destacar-se por sua honestidade, pautar sua vida em valores éticos, ser comprometido, obstinado e ter constância. . $^{8,12,13,15,19,21}$

\section{CONSIDERAÇÕES FINAIS}

A partir dos resultados obtidos, acreditamos que o que faz o bom professor, na percepção dos acadêmicos pesquisados, não é uma ou outra característica isoladamente, mas um conjunto de atributos dos quais podem ser destacados:

- habilidade social,

- interpessoal e

- pedagógica.

Acreditamos que é fundamental estabelecer uma nova relação entre professor e aluno na qual o docente seja capaz de:

- refletir sobre a sua importância na aprendizagem dos alunos;

- buscar caminhos para aperfeiçoar sua prática educativa;

- avaliar constantemente o seu fazer pedagógico; e

- despertar uma consciência crítica no aluno, tornando-o sujeito de sua aprendizagem.

Finalizando, é necessária a democratização e a humanização da relação professor-aluno com a participação de todos os envolvidos. Deve existir a participação efetiva através da discussão e argumentação para que juntos, professor e aluno, possam construir uma relação que estimule a construção do conhecimento, a criação cultural, o desenvolvimento do espírito cientifico e pensamento reflexivo e o comprometimento ético e social como apontam as DCNs.

\section{AGRADECIMENTOS}

Ao Programa de Iniciação Científica Artigo 170/ Governo do Estado de Santa Catarina/Pró-Reitoria de Pesquisa, Pós-Graduação, Extensão e Cultura da Universidade do Vale do Itajaí, pelo financiamento desta pesquisa. 


\section{ABSTRACT}

\section{Characteristics of a good teacher according to the perceptions of dentistry students from the Dental School at UNIVALI}

This study aimed at gaining knowledge into the characteristics of an ideal teacher according to the students of the dentistry course at UNIVALI. It was a descriptive study made according to the results of primary data gathered from a semi-structured interview with 225 students, in the second semester of 2010. It was also an exploratory study designed according to principles of qualitative research. The data collection was structured based on the principles of the Free Word Association Test, prompted by the expression "to me, the ideal teacher is..." The participant had to list up to eight (8) words defining a good teacher in his opinion. Data collection was done by a single researcher. Five categories were defined to conduct the data analysis, according to the characteristics listed by the participants. A total of 225 students from first to last terms of the course answered the data collection questionnaire. To the students, the teacher must have social and interpersonal skills $(37.9 \%)$, teaching skills $(25.9 \%)$, cognitive skills $(14.7 \%)$, organizational skills $(14.1 \%)$ and ethical skills $(7.5 \%)$. The conclusion of this study was that, from the viewpoint of students, a good teacher must have not only knowledge of the subject and teaching skills, but also social and interpersonal skills, and must also be organized and show ethical and professional commitment.

\section{DESCRIPTORS}

Faculty. Dental education. Higher education.

\section{REFERÊNCIAS}

1. Backes DS, Marinho M, Costenaro RS, Nunes S, Rupolo I. Repensando o ser enfermeiro docente na perspectiva do pensamento complexo. Rev. Bras Enferm. 2010; 3(63):421-6.

2. Bariani ICD, Pavani R. Sala de aula na universidade: espaço de relações interpessoais e participação acadêmica. Estud. Psicol. (Campinas) 2008; 1(25): 67-75.

3. Bauer MW, Aarts BA construção do corpus: um princípio para coleta de dados qualitativos. In: Bauer MW, Gaskell G. Pesquisa qualitativa com texto, imagem e som. Petrópolis: Vozes; 2002. p. 39-63.

4. Brasil. Lei de Diretrizes e Bases da Educação Nacional- LDB. Lei $\mathrm{n}^{\circ}$ 9394, de 20 de dezembro de 1996. Disponível em: <http://portal.mec.gov.br/arquivos/pdf/ldb.pdf >. Acesso em: 20 abril 2010.

5. Brasil. Ministério da Saúde. Programa Nacional de Reorientação da Formação Profissional em Saúde - Pró Saúde: objetivos, implementação e desenvolvimento potencial. Brasília: Ministério da Saúde; 2007.
6. Carcereri DL, Amante CJ, Reibnitz MT, Mattevi GS, Silva GG, Padilha ACL, Rath IBS. Formação em odontologia e interdisciplinaridade: o Pró-Saúde da UFSC. Revista daABENO 2011; 11 (1):55-61

7. Cataldi Z, Laje FJ. Um nuevo perfil del professor universitário. Revista de informática educativa y médios audiovisuales 2004; $1(3): 28-33$.

8. Costa NMS. Formação pedagógica de professores de nutrição: uma omissão consentida? Rev. nutr. 2009; 1 (22):97-104.

9. Friedlander MR, Moreira MTA. Formação do enfermeiro: características do professor e o sucesso escolar. Rev. bras. enferm. 2006; 59(1):9-13.

10. Graça TCA. Professor de odontologia: uma visão dos seus atributos sob a óptica discente. Rev ABENO. 2001;1(1):66.

11. Lazzarin HC, Nakama L, Cordoni Jr. L. O papel do professor na percepção dos alunos de odontologia. Saúde Soc.2007; 16(1):90-101.

12. Lazzarin HC, Nakama L, Cordoni Jr. L. Percepção de professores de odontologia no processo ensino-aprendizagem. Ciênc. Saúde coletiva 2010; 15 (supl.1):1801-10.

13. Leadebal ODCP, Fontes WD, Nóbrega MML, Brito Filho GT. Análise das bases didático-pedagógicas para o ensino da sistematização da assistência enfermagem. REME rev. min. Enferm. 2009; 13(1):64-75.

14. Neira RJB, Artacho MCI. Educación en ciencias de la salud: corrientes actuales. Rev. estomatol. Hered.2006; 1(16):73-4.

15. Nimtz MA, Ciampone MHT. O significado de competência para o docente de administração em enfermagem. Rev. Esc. Enferm. USP 2006; 40(3):336-42.

16. Noro LRA, Albuquerque DF, Ferreira, MEM. O desenvolvimento do processo ensino aprendizagem: visão do aluno e do professor. Rev. ABENO 2006; 2(6): 109-14.

17. Raldi DP, Malheiros CF, Fróis IM, Lage-Marques JL. O papel do professor no contexto educacional sob o ponto de vista dos alunos. Rev ABENO 2003; 3(1): 15-23.

18. Rodrigues RM, Coterno SFR. Formação pedagógica na visão de docentes da graduação da área da saúde no Brasil. Rev. enferm. Herediana 2009;1 (2): 3-10.

19. Secco LG, Pereira MLT. Concepções de qualidade de ensino dos coordenadores de graduação: uma análise dos cursos de odontologia do Estado de São Paulo. Interface comum. saúde educ. 2004; 8(15):313-5.

20. Semim GM, Souza MCBM, Corrêa AK. Professor como facilitador do processo ensino-aprendizagem. Rev. gaúcha enferm. 2009; 30(3):484-91.

21. Silva DC, Hernández NN. Conceptualización de los Eestudiantes sobre el buen profesor universitario en las carreras de la salud de la Universidad de La Frontera - Chile. Int. j. morphol. 2008; 26(4):887-92.

Recebido em 09/03/2010 Aceito em 15/06/2010 